\title{
ANALISIS KESULITAN PEMELAJAR BAHASA INDONESIA BAGI PENUTUR ASING (BIPA) DI SAMARKAND STATE INSTITUTE OF FOREIGN LANGUAGES (SAMSIFL), UZBEKISTAN PADA 4 KETERAMPILAN (SKILLS) BERBAHASA
}

\author{
OLEH: \\ JAMALUDDIN NASUTION \\ (UNIVERSITAS PRIMA INDONESIA MEDAN)
}

\begin{abstract}
This research entitles "The Analysis of Difficulties of Indonesian Language for Foreign Speakers (ILFS) Students in Samarkand State Institute of Foreign Languages, Uzbekistan toward 4 Language Skills". There are some language skills, i.e.; (1) listening skills), (2) speaking skills, (3) reading skills, and (4) writing skills. These language skills are the basic of language uses. As a whole, the difficulties faced by students vary, such as intelligence (physical and psychologist factors; intelligence, talent, interest, motivation, and ways of learning) and non-intelligence factors. There are internal and external factors as well (family, school, society factors). This study is to know; (1) what the most difficult language skills students understand, (2) the reasons of students at the difficulties in the language skills, and (3) how the students face their difficulties. The method of this study is descriptive, conducted in ILFS class of English Program and Translation Program at Samarkand State Institute of Foreign Languages, Uzbekistan. The numbers of students are 35 (9 males and 26 females). The time of this study was semester II in 2019, and data was taken in March 2019. Technic of collecting data is using test and interview as well as the evaluation sheet in semester I as the diagnostic data of students' difficulties toward 4 language skills. Data analysis consists of qualitative and quantitative. The lowest average mark is of listening (61.68), speaking (69.07), writing (71.89), and reading (76.29).From the questionnaires' sheet given to the students, it can be concluded that; students like Indonesian language $(85.71 \%)$, the pronunciation of Indonesian language is different to source language $(65.71 \%)$, symbols/letters writing in Indonesian language is not different $(80.00 \%)$, there is no difficulty in uttering Indonesian language words $(77.14 \%)$, guidance book used in learning process is good and helpful Indonesia $(91.43 \%)$, in listening, speaker speaks very fast $(97.14 \%)$, difficulties in listening $(94.29 \%)$, there is no difficulty in reading skills $(85.71 \%)$, there is no difficulty in writing skills $(80.00 \%)$, there is difficulty in speaking skills $(71.43 \%)$, the most liked language skills in learning is reading (57.14\%), the most hated language skills in learning is listening (94.29\%), the most difficult language skills in learning is listening $(88.57 \%)$, the easiest language skills in learning is reading $(71.43 \%)$, and the students' action facing the difficulties in learning Indonesian language is asking the teacher $(85.71 \%)$. It is expected that the ILFS teaching concerns on students' difficulties firstly and give motivation during the teaching process in order that the students are motivated to learn Indonesian language.
\end{abstract}

Key words: difficulties, language skills, students' of ILFS 


\section{PENDAHULUAN}

\section{Latarbelakang}

Bahasa Indonesia bagi Penutur Asing atau disingkat dengan BIPA (kemudian disebut BIPA) adalah sebuah program pembelajaran bahasa Indonesia yang subjeknya merupakanpemelajar asing. BIPA ini lebih memfokuskan pada pemelajar itu sendiri.Orang-orangyang menjadi subjek BIPA adalah orang asing baik yang tinggal di Indonesia ataupun yang berada di negaranya sendiri.Sehingga bahasa Indonesia adalah bahasa asing bagi pemelajar BIPA tersebut.Pembelajaran BIPA menjadikanorang asing tersebut mampu atau menguasai bahasa Indonesia (Kusmiatun, 2016).

Seperti yang disebutkan bahwa pemelajar BIPA adalah pelajar dari luar negara Indonesia yang ingin belajarbahasa Indonesia. Pemelajar tersebut biasanya terdiri dari warga negara asing yang belummengerti dasar dan tata bahasa Indonesia tetapi tertarik untuk mempelajarinya.Pemelajar BIPA merupakan pelajar berkewarganegaraan asing yang memiliki latar belakang budaya berbeda dengan budaya bahasa yang diketahui dan dipelajarinya (Suyitno, 2008).Pemelajar BIPA dapat diibaratkan sebagai seorang anak yang belum mengetahuiapapun mengenai bahasa yang akan digunakan di lingkungannya. Pengetahuan merekatentang penggunaan bahasa Indonesia dengan benar dan baik masih terlalu awam danprematur. Dan bisa dikatakan bahwa bahasa Indonesia untuk Penutur Asing dapat diumpamakan sebagai sosok bayi yangbaru lahir dan perlu didewasakan. Proses pendewasaan tersebut harus dilakukan secaraprofesional diiringi dengan tanggung jawab keilmuan yang melibatkan berbagai pihak.

Jika bicara eksistensi bahasa Indonesia, sangat diharapkan bahwabahasa Indonesia mampu menjadi bahasa budaya danbahasa Ilmu Pengetahuan dan Teknologi (IPTEK) yang berwibawa di tengah dahsyatnya arus globalisasi. Sikap 
terbuka dantidak kaku harus ditunjukkan dalam mengikuti kemajuan global. Masyarakat pundiharapkan setia dan bangga sebagai penutur dalam menggunakan bahasa Indonesiasebagai bahasa komunikasi yang efektif dalam menghadapi era masyarakat ekonomiASEAN saat ini (Ngelu, 2015). Salah satu upayanya yaitu melalui pengajaranBIPA. Dan perkembangan bahasa Indonesia bagi penutur asing (BIPA) semakin maju saat ini dikancah internasional. BIPA tidak hanya diminati di kawasan ASEAN, tetapi juga diwilayah Asia dan Australia. Hal tersebut salah satunya terbukti dengan adanyainformasi tentang minat pelajar bahasa Indonesia yang semakin tinggi dari berbagaimedia cetak maupun online. Selain di kawasan ASEAN, Asia, dan Australia, BIPAjuga dijadikan mata kuliah di beberapa universitas di Eropa.

Rafiek (2014) mengungkapkan bahwa peluang bahasa Indonesia untukdikembangkan menjadi bahasa Internasional paling tidak di Asia dan Asia Tenggaramemang terbuka lebar. Bahasa Indonesia telah diajarkan di beberapa universitas-universitasdi luar negeri, misalnya Rusia, Jepang, Amerika Serikat, Australia, Cina,Jerman, dan lain-lain.Sementara itu menurut Soegihartono (2012) pengajaranBIPA telah tersebar di seluruh benua dengan 179 lembaga penyelenggara.Lembaga-lembaga tersebutmisalnyaperguruantinggi, KBRI, pusatpusat kebudayaan, sekolahIndonesia di luar negeri dan lembaga-lembaga kursus lainnya.Dalamsalah satu presentasi sidang pleno Kongres IXBahasa Indonesia, diungkapkan bahwapada saat ini ada 45 negara yangadamengajarkan bahasa Indonesia, seperti Australia, Amerika, Kanada, Vietnam, danbanyaknegara lainnya. Dan salah satu pengajaran BIPA yang telah dimulai sejak tahun 2014 adalah negara Uzbekistan. Ada 3 universitas yang menjadikan bahasa Indonesia sebagai mata kuliah wajib bagi mahasiswanya, yakni World Language University di Tashkent, Oriental Language Studies University di Tashkent, dan Samarkand State Institute of Foreign Languages (SamSIFL) di Samarkand. Dan fokus penelitian ini adalah pengajaran BIPA yang dilaksanakan di Samarkand State Institute of Foreign Languages.

Banyak alasan dan tujuan orang belajar bahasa Indonesia dalam hal ini BIPA. Seperti yang disampaikan oleh Suyitno (2008) bahwa tujuan utama pelajar 
asing belajarBIPA adalah tentunya untuk memperlancar berbahasa Indonesia dan mengenal budayaIndonesia lebih dalam lagi. Kelancaran berbahasa Indonesia tersebut diperlukan olehpara pelajar BIPA karena; (1) para pelajar BIPA tersebut mengambil program tentangIndonesia di universitas asalnya; (2) pelajar BIPA akan melakukan beberapa penelitiandi Indonesia; (3) pelajar BIPA akan bekerja di Indonesi; (4) pelajar BIPA akanmeneliti masalah tentang bahasa Indonesia; dan (5) pelajar BIPA berencana akantinggal di Indonesia dalam waktu yang lama. Dalam usaha mengembangkan dan meningkatkan kemampuan berbahasa, terkhusus pemelajar BIPA, diperlukan suatu proses yang mampu melibatkan banyak keterampilan dalam pembelajaran berbahasa. Ada beberapa keterampilan (skills), dan Tarigan (2013) menjelaskan mengenai keterampilan-keterampilan berbahasa tersebut mempunyai empat komponen, yaitu: (1) keterampilan menyimak/mendengarkan (listening skills), (2) keterampilan berbicara (speaking skills), (3) keterampilan membaca (reading skills), dan (4) keterampilan menulis (writing skills). Keterampilan-keterampilan tersebut yang kemudian mendasari kemampuan berbahasa.Keterampilan-keterampilan tersebut erat kaitannya dengan pembelajaran berbahasa dan kegiatan berbahasa sehingga diharapkan bahwa semua keterampilan yang disebutkan di atas bisa dikuasai oleh pemelajar BIPA. Dengan penguasaan yang baik dari semua aspek keterampilan (skills)akan membuat pemelajar BIPA (pemelajar asing) memperoleh hasil maksimal sesuai dengan tujuan/alasan mereka mempelajari bahasa Indonesia seperti yang telah dijelaskan sebelumnya.

Dalam usaha untuk menguasai keterampilan (skills) tersebut terkadang muncul kendala ataupun kesulitan dalam proses belajar. Secara umum kesulitan yang dihadapi pemelajar bermacam-macam, adapun kesulitan belajar menurut Djamarah (2006) dikelompokkan menjadi 4 macam yaitu: (1) dilihat dari segi kesulitan belajar, ada yang berat dan ada yang ringan, (2) dilihat dari mata pelajaran yang dipelajari, yakni ada yang sebagaian mata pelajaran dan ada pula yang sifatnya sementara, (3) dilihat dari sifat kesulitannya, ada yang sifatnya menetap dan ada yang sifatnya sementara, dan (4) jika dilihat dari segi faktor penyebabnya, yakni faktor intelegensi dan faktor nonintelegensi. 
Menurut Slameto (2005), faktor-faktor penyebabkesulitan belajar adalah;

\section{Faktor internal}

Faktor internal adalah faktor yang bersumber dari dalam diri individu itusendiri dalam mencapai tujuan belajar.Faktor internal ini sangat besarpengaruhnya tetapi tidak disadari karenadianggap suatu hal yang biasa, sebenarnyafaktor ini dapat dibagi dua bagian yaitufaktor fisilogis dan faktor psikologis.

a. Faktor fisiologis

Faktor fisiologis adalah faktor yangbersumber dari dalam individu yang erathubungannya dengan masalahkejasmanian terutam tentang fungsi alatalatpancaindera,karenapancainderainimerupakan pintu masuk perangsang dariluar kedalam individu.

b. Faktor psikologis

Faktor-faktor psikologis yangmempengaruhi proses belajar pemelajar antaralain:

1) Kecerdasan (intelegensi)

2) Bakat

3) Minat

4) Motivasi

5) Cara belajar

2. Faktor eksternal

Faktor eksternal adalah faktor yangberasal dari luar diri pemelajar yang dapatmempengaruhi prestasi pemelajar.Faktoreksternal yang dapat mempengaruhiprestasi seseorang ada tiga yaitu faktorkeluarga, faktor sekolah, dan faktormasyarakat.

Harapan atau ekspektasi terkadang tidak selalu sesuai dengan kenyataan atau realita yang terjadi dalam proses belajar mengajar. Pada pengajaran yang telah dilaksanakan di Samarkand State Institute of Foreign Languages (SamSIFL) pada semester I tahun ajaran 2018/2019 diperoleh hasil yang tidak terlalu menggembirakan. Dari keempat keterampilan (skills) berbicara tersebut, nilai rata-rata pemelajar ada yang di atas KKM 65 dan ada yang di bawahnya. Dari pengamatan sementara dari hasil seluruh ujian bulanan (September - Desember 
2018), nilai rata-rata kelas terendah adalah menyimak (listening) yakni 61,68 dan masih di bawah nilai KKM 65. Disusuloleh nilairata-rata berbicara (speaking) yaitu 69,07, dan kemudiannilaimenulis (writing), yaitu nilai rata-rata 71,89. Dan nilai rata-rata terbaik adalah membaca (reading)yakni 76,29.

Dari data sementara yang diperoleh di semester I, maka penulis tertarik untuk mengetahui dan meneliti; (1) apa keterampilan (skills) berbahasa yang tersulit dipahami oleh pemelajar? (2) kenapa pemelajar kesulitan dalam mempelajari keterampilan (skills) berbahasa tersebut? dan (3) bagaimana pemelajar mengatasi kesulitan tersebut?

\section{METODE PENELITIAN}

Metode penelitian ini adalah penelitian deskriptif yang berfokus pada pertanyaan "bagaimana (how)" dan metode penelitian eksplanatif yang bertujuan untuk memberikan penjelasan mengapa sesuatu terjadi atau menjawab pertanyaan "mengapa (why)". Penelitianinidilaksanakandikelas Bahasa Indonesia bagi Penutur Asing (BIPA) level A-1 Jurusan Bahasa Inggris dan Jurusan Terjemahan di Samarkand State Institute of Foreign Languages, Uzbekistan.Jumlahsubjekdalampenelitianiniadalah 35 orang pemelajar, dimana pemelajar laki-lakiberjumlah 9 orang dan pemelajar perempuan berjumlah 26 orang.Waktu penelitian dilaksanakan pada semester II tahun 2019, dan data diambil pada bulan Maret 2019.

Teknik pengumpulan data menggunakan tes dan wawancara.Hasil tes/ujian semester I yang sudah dilakukan dibuat menjadi data tentang diagnosis kesulitan belajar para pemelajar terhadap 4 keterampilan (skills) berbahasa. Kuesiner yang berhubungan dengan masalah kesulitan pemelajar dalam memahami materi di 4 keterampilan berbahasa serta wawancara dilakukan juga kepada pemelajar untuk menggali informasi mengenai kesulitan yang mereka hadapi.

Teknik analisis data penelitian terdiri atas dua jenis, yaitu data yang bersifat kualitatif dan kuantitatif.Data kualitatif meliputi deskripsi data mengenai kesulitan pemelajar dalam 4 keterampilan (skills) berbahasa.Analisis kuantitatif 
menggunakan teknis analisis statistik sederhana.Teknik analisis statistik sederhana yang dimaksud berupa analisis persentase (Arikunto, 2010).Teknik analisis ini digunakan peneliti untuk menghitung persentase skor pencapaian pemelajar pada hasil ujian semester I sebagai gambaran pada ke 4 keterampilan (skills) berbahasa tersebut.

\section{HASIL PENELITIAN DAN PEMEBAHASAN}

\section{HASIL PENELITIAN}

Dalam pembelajaran Bahasa Indonesia bagi penutur Asing (BIPA), dimana pemelajarnya adalah orang asing yang tidak mampu berbahasa Indonesia, dan bahasa Indonesia sebagai bahasa asing bagi mereka, maka pembelajaran seyogianya harus mengedepankan 4 keterampilan (skills) berbahasa. Pembelajaran dimulai awal September sampai dengan Desember 2018, dengan jumlah tatap muka 2 x setiap minggu (@80 menit).Buku ajar yang digunakan sebagai sumber utama, yakni Buku Sahabatku Indonesiayang diterbitkan oleh Penerbit Pusat Pengembangan Strategi dan Diplomasi Kebahasaan Badan Pengembangan dan Pembinaan Bahasa Kementerian Pendidikan dan Kebudayaan tahun 2017.Urutan pengajaran adalah (1) menyimak, (2) membaca, (3) menulis, dan (4) berbicara dimana masing-masing diberikan 2 kali pertemuan dengan tema/unit materi yang sama.

Di akhir bulan atau setiap akhir sebuah topik, diberikan ujian bulanan yang 90\% adalah dari materi yang telah diajarkan.Ujian dilakukan dengan ketat dan terstruktur untuk melihat kemampuan asli para pemelajar.Dari semua hasil ujian tersebut, diperoleh frekuensi nilai yang serupa setiap bulannya.Nilai ujian berurutan dari yang terendah ke yang tertinggi adalah (1) menyimak, (2) berbicara, (3) menulis, dan (4) membaca.Hasil tersebut seperti terlihat dalam tabel dan diagram berikut. 
Tabel 1: Hasil Ujian pemelajar BIPA SamSIFL periode September - Desember 2018 per keterampilan (skills) berbahasa

\begin{tabular}{ccccc}
\hline \multirow{2}{*}{ Ujian di Bulan } & \multicolumn{4}{c}{ Keterampilan (Skills) } \\
\cline { 2 - 5 } & Menyimak & Membaca & Menulis & Berbicara \\
\hline September & 61,71 & 78,29 & 73,29 & 70,57 \\
\hline Oktober & 60,14 & 74,86 & 72,00 & 69,14 \\
\hline November & 61,57 & 74,00 & 69,57 & 65,57 \\
\hline Desember & 63,29 & 78,00 & 72,71 & 71,00 \\
\hline
\end{tabular}

Untuk memudahkan melihat gambaran secara umum, hasil dari tabel di atas dapat terlihat seperti diagram berikut;

Diagram 1: Hasil Ujian pemelajar BIPA SamSIFL periode September - Desember 2018 per keterampilan (skills) berbahasa

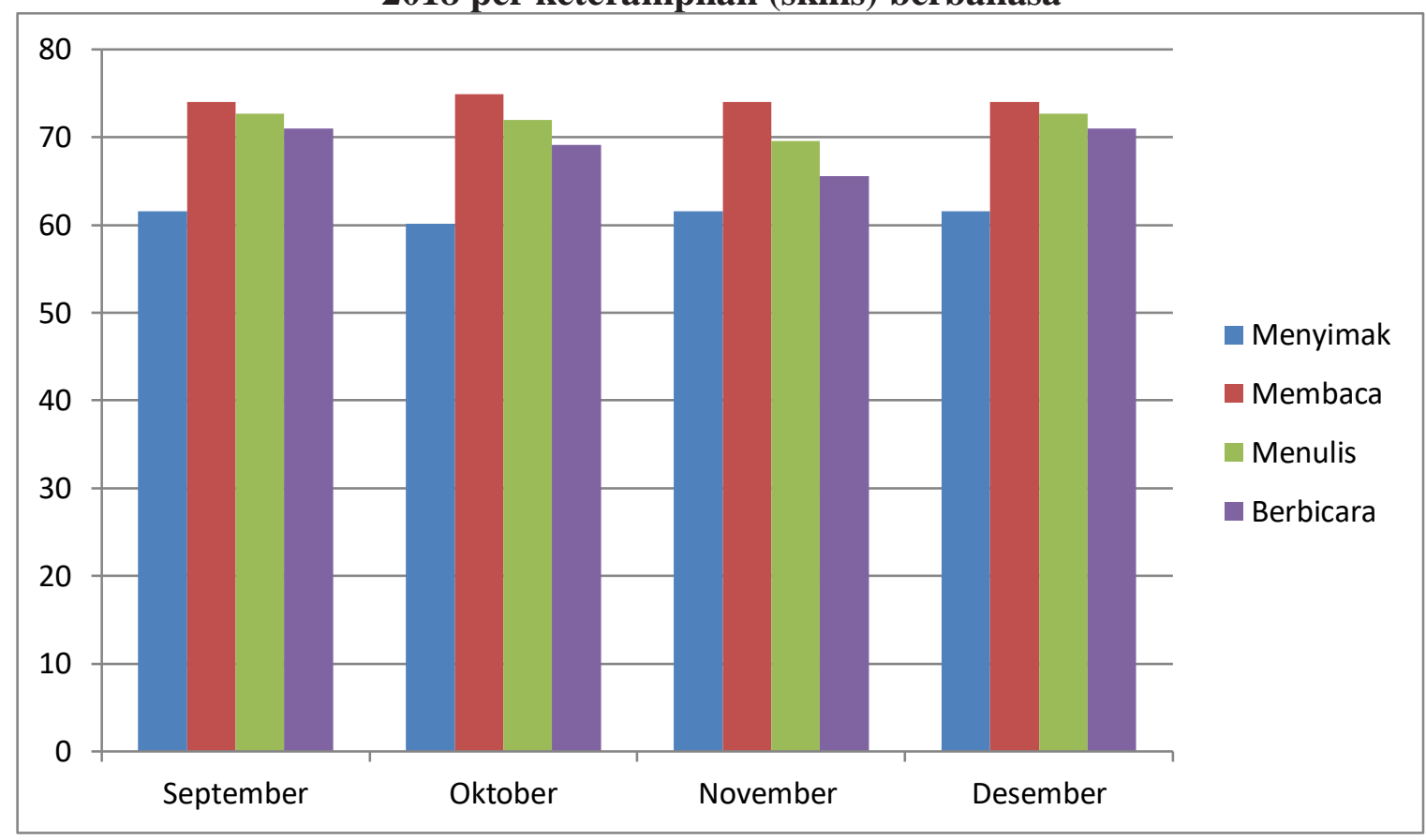

Untuk menjawab pertanyaan tentang apa keterampilan (skills) apa yang tersulit dipahami oleh pemelajar, kenapa pemelajar kesulitan dalam mempelajari keterampilan (skills) tersebut? Danbagaimana pemelajar mengatasi kesulitan tersebut, maka diberikan kuesioner dan melakukan wawancara pada para pemelajar.Item pertanyaan pada kuesioner dan wawancara diberikan dalam 2 versi bahasa, yakni bahasa Indonesia dan bahasa Inggris untuk menghindari kesalahpahaman dalam menjawab. Data yang diperoleh dari hasil kuesioner adalah sebagai berikut;

Tabel 2: Hasil Analisa Kuesioner Pemelajar BIPA SamSIFL

\begin{tabular}{|c|c|c|c|c|}
\hline \multirow{2}{*}{ Item Pertanyaan } & \multicolumn{4}{|c|}{ Persentase (\%) } \\
\hline & $\mathbf{Y a}$ & Tidak & Sedang & Sedikit \\
\hline 1. Menyukai bahasa Indonesia & 85.71 & 2.86 & 2.86 & 8.57 \\
\hline 2. Pengucapan kata bahasa Indonesia berbeda & 65.71 & 2.86 & 14.29 & 17.14 \\
\hline
\end{tabular}


dengan bahasa ibu (bahasa sumber)

\begin{tabular}{|c|c|c|c|c|}
\hline $\begin{array}{l}\text { 3. Penulisan simbol/huruf di bahasa Indonesia } \\
\text { berbeda dengan yang didengar }\end{array}$ & 0.00 & 80.00 & 14.29 & 5.71 \\
\hline $\begin{array}{l}\text { 4. Kesulitan dalam mengucapkan kata-kata bahasa } \\
\text { Indonesia }\end{array}$ & 2.86 & 77.14 & 14.29 & 5.71 \\
\hline $\begin{array}{l}\text { 5. Buku panduan yang digunakan bagus dan } \\
\text { membantu dalam belajar bahasa Indonesia }\end{array}$ & 91.43 & 0.00 & 5.71 & 2.86 \\
\hline $\begin{array}{l}\text { 6. Dalam menyimak, si pembicara berbicara } \\
\text { terlalu cepat }\end{array}$ & 97.14 & 0.00 & 2.86 & 0.00 \\
\hline 7. Kesulitan dalam keterampilan menyimak & 94.29 & 2.86 & 2.86 & 0.00 \\
\hline 8. Kesulitan dalam keterampilan membaca & 2.86 & 85.71 & 5.71 & 5.71 \\
\hline 9. Kesulitan dalam keterampilan menulis & 5.71 & 80.00 & 5.71 & 8.57 \\
\hline 10. Kesulitan dalam keterampilan berbicara & 71.43 & 2.86 & 14.29 & 11.43 \\
\hline \multirow{2}{*}{ Item Pertanyaan } & \multicolumn{4}{|c|}{ Persentase (\%) } \\
\hline & Menyimak & Membaca & Menulis & Berbicara \\
\hline $\begin{array}{l}\text { 11. Keterampilan yang paling disukai dalam belajar } \\
\text { bahasa Indonesia }\end{array}$ & 0.00 & 57.14 & 28.57 & 14.29 \\
\hline $\begin{array}{l}\text { 12. Keterampilan yang paling tidak disukai dalam } \\
\text { belajar bahasa Indonesia }\end{array}$ & 94.29 & 0.00 & 0.00 & 5.71 \\
\hline $\begin{array}{l}\text { 13. Keterampilan yang paling sulit dalam belajar } \\
\text { bahasa Indonesia }\end{array}$ & 88.57 & 0.00 & 2.86 & 8.57 \\
\hline $\begin{array}{l}\text { 14. Keterampilan yang paling mudah/gampang } \\
\text { dalam belajar bahasa Indonesia }\end{array}$ & 0.00 & 71.43 & 14.29 & 14.29 \\
\hline \multirow[t]{2}{*}{ Item Pertanyaan } & \multicolumn{4}{|c|}{ Persentase (\%) } \\
\hline & $\begin{array}{c}\text { Bertanya } \\
\text { pada guru }\end{array}$ & $\begin{array}{c}\text { Bertanya } \\
\text { pada teman }\end{array}$ & $\begin{array}{c}\text { Melihat } \\
\text { kamus / } \\
\text { buku }\end{array}$ & $\begin{array}{c}\text { Tidak } \\
\text { melakukan } \\
\text { apapun }\end{array}$ \\
\hline $\begin{array}{l}\text { 15. Tindakan pemelajar jika menghadapi kesulitan } \\
\text { dalam belajar bahasa Indonesian }\end{array}$ & 85.71 & 8.57 & 5.71 & 0.00 \\
\hline
\end{tabular}

\section{PEMBAHASAN}

Dari hasil ujian pemelajar BIPA di Samarkand State Institute of Foreign Languages (SamSIFL) pada periode September - Desember 2018 per keterampilan (skills) berbahasa ditemukan hasil yang variatif.Keterampilan menyimak dari bulan September hingga Desember 2018 tidak melewati nilai KKM 65.Kemampuan para mahasiswa dalam keterampilan menyimak bisa dikategorikan "buruk".

Dari hasil kuesioner dan interview diperoleh beberapa alasan kenapa nilai rata-rata mahasiswa "buruk" dalam keterampilan ini.Alasan tersebut bisa dikategorikan secara faktor internal dan eksternal. Faktor internal adalah item pertanyaan nomor 12 apa keterampilan yang paling tidak disukai dalam belajar bahasa Indonesia adalah menyimak (94.29\%) dan nomor 13 yakni keterampilan yang paling sulit dalam belajar bahasa Indonesia $(88.57 \%)$.

Dalam faktor psikologis, yang mempengaruhi proses belajar pemelajar antara lain adalah kecerdasan (intelegensi), bakat, minat, motivasi, dan cara belajar. Dari jawaban kuesioner serta hasil wawancara sudah menunjukkan bahwa minat mahasiswa rendah di keterampilan berbahasa menyimak (listening). 
Faktor psikologis lainnya adalah "cara belajar". Jawaban para mahasiswa di item pertanyaan nomor 15 tentang tindakan pemelajar jika menghadapi kesulitan dalam belajar bahasa Indonesian adalah bertanya pada guru (85.71\%), bertanya pada teman $(8.57 \%)$, melihat kamus/buku (5.71\%), dan tidak melakukan apapun $(0.00 \%)$. Jawaban dominan adalah bertanya pada guru, dan hal ini mengindikasikan bahwa para pemelajar belum mandiri (independent) dalam proses pembelajaran. Alasan yang diperoleh saat wawancara adalah para pemelajar belum yakin jika bertanya pada teman dan efisiensi waktu apabila bertanya pada guru.

Rendahnya nilai menyimak (listening) pemelajar juga tidak lepas dari faktor eksternal.Faktor eksternal adalah faktor yang berasal dari luar diri pemelajar yang dapat mempengaruhi prestasi pemelajar seperti fasilitas belajar yang digunakan. Dalam pembelajaran BIPA di kampus SamSIFL Uzbekistan ini buku ajar yang digunakan adalah Buku Sahabatku Indonesia yang diterbitkan oleh Penerbit Pusat Pengembangan Strategi dan Diplomasi Kebahasaan Badan Pengembangan dan Pembinaan Bahasa Kementerian Pendidikan dan Kebudayaan tahun 2017. Item pertanyaan nomor 5 dan 6 di kuesioner merupakan faktor eksternal. Pertanyaan nomor 5, apakah buku panduan yang digunakan bagus dan membantu dalam belajar bahasa Indonesia dijawab 91.43\%. Keterampilan menyimak (listening) dirasakan oleh pemelajar sangat sulit karena si pembicara berbicara terlalu cepat (97.14\%). Para mahasiswa tersebut merupakan pemelajar BIPA level A-1, belum terbiasa dengan bahasa Indonesia.

Karena menyimak (listening) berhubungan dengan berbicara (speaking), membuat nilai terendah kedua adalah berbicara. Walaupun item pertanyaan nomor 4 kesulitan dalam mengucapkan kata-kata bahasa Indonesia dirasakan oleh pemelajar tidak sulit (77.14\%), hanya $2.86 \%$ yang menjawab bahwa kata-kata bahasa Indonesia sulit, namun kesulitan dalam berbicara tetap dirasakan oleh pemelajar. Hal ini terlihat dari jawaban pertanyaan nomor 10 , yakni $71.43 \%$ merasa bahwa keterampilan berbicara sulit. Alasan untuk hal ini adalah bahwa para pemelajar belum terbiasa dengan kalimat-kalimat bahasa Indonesia.Diperoleh juga jawaban saat wawancara bahwa struktur/tata bahasa ibu (bahasa Uzbek) jauh berbeda dengan bahasa Indonesia. Cara menyusun kata dalam kalimat juga jauh berbeda sehingga sering muncul kesalahan dalam mengungkapkan sebuah kalimat bahasa Indonesia yang baik dan benar.

Keterampilan (skills) membaca adalah yang paling tinggi, tentu hal ini adalah kebalikan dari menyimak (listening). Item pertanyaan nomor 11, keterampilan yang paling 
disukai dalam belajar bahasa Indonesia adalah membaca (57.14\%), kemudian menulis (28.57\%), dan berbicara (14.29\%). Item pertanyaan nomor 14, keterampilan yang paling mudah/gampang dalam belajar bahasa Indonesia adalah membaca $(71.43 \%)$. Hal ini bisa dikategorikan kepada faktor internal karena adanya minat dalam diri pemelajar BIPA tersebut, mereka menyukai keterampilan membaca ini karena mudah.

Dalam wawancara diperoleh jawaban pemelajar bahwa bahasa Indonesia tidak begitu jauh berbeda dengan bahasa Uzbek sebagai bahasa ibu. Ini juga terlihat dari jawaban para mahasiswa di item pertanyaan nomor 2, pengucapan kata bahasa Indonesia berbeda dengan bahasa ibu (bahasa sumber) dengan persentase $2.86 \%$ menjawab tidak berbeda dan $17.14 \%$ menjawab sedikit saja perbedaannya, dan $14.29 \%$ menjawab sedang. Dominasi jawaban bahwa $65.71 \%$ pemelajar mengatakan bahwa pengucapan kata bahasa Indonesia berbeda dengan bahasa ibu (bahasa sumber). Item pertanyaan nomor 3, penulisan simbol/huruf di bahasa Indonesia tidak berbeda dengan yang didengar $(80.00 \%)$ hanya $14.29 \%$ menjawab ada perbedaan dalam tingkatan "sedang". Untuk pertanyaan nomor 4 di kuesioner yakni kesulitan dalam mengucapkan kata-kata bahasa Indonesia, $77.14 \%$ pemelajar menjawab "tidak" dan hanya $2.86 \%$ menjawab bahwa mereka menemukan kesulitan dalam mengucapkan kata-kata bahasa Indonesia tersebut. Jawaban para mahasiswa bahwa bahasa Indonesia tidak begitu jauh perbedaannya dengan bahasa ibu (bahasa Uzbek) bisa dikategorikan sebagai faktor eksternal.

\section{PENUTUP}

Dari hasil kuesioner yang diberikan pada pemelajar dapat disimpulkan bahwa:

1. Pemelajar menyukai bahasa Indonesia $(85.71 \%)$.

2. Pengucapan kata bahasa Indonesia berbeda dengan bahasa ibu/bahasa sumber $(65.71 \%)$.

3. Penulisan simbol/huruf di bahasa Indonesia tidak berbeda dengan yang didengar $(80.00 \%)$.

4. Tidak mengalami kesulitan dalam mengucapkan kata-kata bahasa Indonesia (77.14\%).

5. Buku panduan yang digunakan bagus dan membantu dalam belajar bahasa Indonesia $(91.43 \%)$.

6. Dalam menyimak, si pembicara berbicara terlalu cepat $(97.14 \%)$.

7. Kesulitan dalam keterampilan menyimak (94.29\%).

8. Tidak mengalami kesulitan dalam keterampilan membaca $(85.71 \%)$. 
9. Tidak mengalami kesulitan dalam keterampilan menulis $(80.00 \%)$.

10. Mengalami kesulitan dalam keterampilan berbicara $(71.43 \%)$.

11. Keterampilan yang paling disukai dalam belajar bahasa Indonesia adalah membaca $(57.14 \%)$.

12. Keterampilan yang paling tidak disukai dalam belajar bahasa Indonesia adalah menyimak (94.29\%)

13. Keterampilan yang paling sulit dalam belajar bahasa Indonesia adalah menyimak $(88.57 \%)$.

14. Keterampilan yang paling mudah/gampang dalam belajar bahasa Indonesia adalah membaca $(71.43 \%)$.

15. Tindakan pemelajar jika menghadapi kesulitan dalam belajar bahasa Indonesian adalah bertanya pada guru $(85.71 \%)$.

Dari uraian temuan dan pembahasan di atas, dapat disimpulkan bahwa kesulitan pemelajar BIPA dalam keterampilan (skills) berbahasa sama dan sesuai dengan teori-teori yang sudah dipaparkan oleh para ahli. Kesulitan-kesulitan tersebut muncul karena faktor internal (dalam) dan eksternal (luar) pemelajar BIPA itu sendiri. Pemelajar BIPA di Samarkand State Institute of Foreign Languages (SamSIFL) adalah pemelajar yang menyenangi pengajaran bahasa Indonesia $(85.71 \%)$. Ini merupakan faktor internal yang positif pada proses pembelajaran BIPA itu sendiri. Namun untuk kesulitan dalam pemahaman keterampilan (skills) berbahasa menjadi hal yang penting diatasi.

Urutan keterampilan (skills) berbahasa yang tersulit dipahami oleh pemelajar BIPA di SamSIFL adalah (1) menyimak, (2) berbicara, (3) menulis, dan (4) membaca.Kesimpulan ini diperoleh dari hasil/nilai ujian bulanan pada periode semester I di bulan September - Desember 2018. Alasan kenapa pemelajar BIPA tersebut mengalami kesulitan dalam menyimak (listening) adalah; (1) Pengucapan kata bahasa Indonesia berbeda dengan bahasa ibu/bahasa sumber (65.71\%), (2) dalam simakan di buku ajar yang digunakan, pembicara berbicara terlalu cepat (97.14\%), (3) menyinak adalah keterampilan yang paling tidak disukai dalam belajar bahasa Indonesia (94.29\%), dan (4) keterampilan yang paling sulit dalam belajar bahasa Indonesia adalah menyimak (88.57\%).

Untuk menjawab pertanyaan bahwa bagaimana pemelajar mengatasi kesulitan tersebut, diperoleh jawaban dominan adalah bertanya pada guru $(85.71 \%)$, bertanya pada teman (8.57\%), melihat kamus/buku $(5.71 \%)$, dan tidak melakukan apapun $(0.00 \%)$. Ketergantungan pemelajar pada guru masih menjadi faktor penghalang dalam 
belajar.Pemelajar BIPA di SamSIFL belum sepenuhnya menjadi pemelajar yang mandiri.Diperoleh juga jawaban dari wawancara bahwa hal ini dipengaruhi oleh belum lengkapnya fasilitas yang diperoleh seperti kamus bahasa Uzbek - Indonesia masih terbatas. Diharapkan agar pengajaran BIPA memperhatikan kesulitan pemelajar BIPA terlebih dahulu.Susunan keterampilan (skills) berbahasa buku ajar BIPA yang digunakan tidak selamanya sesuai dengan kebutuhan pemelajar itu sendiri.Untuk menghindari tekanan psikologis (internal) pemelajar maka disarankan pengajaran keterampilan (skills) berbahasa mengikuti kemampuan pemelajar yang tertinggi. Apabila pemelajar BIPA merasa tidak terbebani dengan kesulitan-kesulitan pembelajaran, akan memberi dorongan semangat bagi mereka untuk terus mempelajari bahasa Indonesia.

Pengajar BIPA juga diharapkan mampu memberi motivasi dalam pengajaran agar pemelajar terdorong untuk belajar bahasa Indonesia.Motivasi tersebut merupakan menjadi alat untuk mengatasi faktor internal kesulitan memahami materi pengajaran.Diharapkan juga agar pengajar dan institusi penyelenggara pengajaran BIPA bisa memfasilitasi kebutuhan pengajaran sebagai solusi untuk mengatasi faktor eksternal kesulitan pemelajar BIPA, seperti buku ajar yang sesuai, kamus, dan alat-alat peraga lainnya. Implikasi penelitian ini adalah rekomendasi untuk pengajar dan institusi untuk jeli melihat faktorfaktor kesulitan pemelajar BIPA dalam pembelajaran BIPA. Penelitian ini juga memberi ruang bagi penelitian lain agar dapat meningkatkan kualitas pengajaran BIPA terkhusus di luar negeri. Pengajaran bahasa Indonesia di luar negeri adalah salah satu upaya Indonesia menginternasionalisasikan bahasa negara, media memperkenalkan Indonesia sehingga negara Indonesia bisa sejajar dengan negara-negara maju lainnya.

\section{DAFTAR PUSTAKA}

Arikunto, S. 2010. Prosedur Penelitian Suatu Pendekatan Praktik. Jakarta: Rineka Cipta

Kusmiatun, Ari. (2016). Mengenal BIPA dan Pembelajarannya. Yogyakarta:K Media Ngelu,Maria

Rafiek, M. (2014).Bahasa Indonesia sebagai Bahasa Persatuan Indonesia: Kenyataan, Tantangan, dan Peluang bagi Pengembangan dan Pembinaan Bahasa. Makalah disajikanada Seminar Kebahasaan dalam Rangka Hari Sumpah Pemuda. Banjarmasin: BalaiBahasa Provinsi Kalimantan Selatan.

Santisima.(2015). Eksistensi Bahasa Indonesia di Mata Dunia pada EraMEA. Makalah 
disajikan pada Seminar Nasional Pendidikan Bahasa Indonesia.Surakarta: Universitas Muhammadiyah Surakarta.

Slameto, 2005.Belajar dan Faktor-faktor Yang Mempengaruhinya. Jakarta: PT. Rineka Cipta.

Soegihartono, A. (2012). Pembakuan Pembelajaran Bahasa Indonesia bagi PenuturAsing sebagai Sarana Pengenalan Budaya Indonesia. Makalah ini disajikandalam International Conference on Indonesian Studies. Depok: Fakultas IlmuPengetahuan Budaya, Universitas Indonesia.

Suyitno, Imam. (2008). Norma Pedagogis dan Analisis Kebutuhan Belajar dalam Pembelajaran Bahasa Indonesia untuk Penutur Asing (BIPA).Diksi, 15 (1), pp:111-119.

Tarigan, H. G. (2013). Berbicara sebagai suatu keterampilan berbahasa. Bandung: Angkasa. 